\title{
Intracranial Vascular Malformations and Epilepsy
}

\author{
Colin B. Josephson, MD, MSc ${ }^{1}$ Felix Rosenow, $\mathrm{MD}^{2,3}$ \\ ${ }^{1}$ Department of Clinical Neurosciences, University of Calgary, Calgary, \\ AB, Canada \\ 2 Epilepsy Center Frankfurt Rhine-Main, Department of Neurology, \\ Center of Neurology and Neurosurgery, Goethe-University Frankfurt, \\ Frankfurt a.M.; Germany \\ ${ }^{3}$ Epilepsy Center Hessen, Department of Neurology, Philipps- \\ University Marburg, Marburg, Germany \\ ${ }^{4}$ Division of Clinical Neurosciences, Centre for Clinical Brain Sciences, \\ University of Edinburgh, Edinburgh, United Kingdom
}

Rustam Al-Shahi Salman, PhD 4

Address for correspondence Rustam Al-Shahi Salman, PhD, FU303i, Centre for Clinical Brain Sciences, First Floor, Chancellor's Building, University of Edinburgh, 49 Little France Crescent, Edinburgh, EH16 4SB, United Kingdom (e-mail: Rustam.Al-Shahi@ed.ac.uk).

Semin Neurol 2015;35:223-234.

\begin{abstract}
Keywords

- arteriovenous malformations

- cavernous malformations

- epilepsy

- antiepileptic drugs

- epilepsy surgery

Among the spectrum of intracranial vascular malformations (IVMs), arteriovenous malformations (AVMs), and cavernous malformations (CCMs) are of particular importance for epilepsy. Seizures are a common mode of presentation for both conditions. Seizures may occur de novo or secondary to intracerebral hemorrhage. Timely imaging is thus crucial for patients with seizures and AVMs or CCMs. Patients with a first-ever AVM- or CCM-related seizure can now be considered to have epilepsy according to the International League Against Epilepsy criteria. Observational studies and case series suggest that between 45 to $78 \%$ of patients with AVM-related epilepsy and 47 to $60 \%$ of patients with CCM-related epilepsy may achieve seizure freedom through antiepileptic drugs (AEDs) alone. Invasive procedures are available although current evidence suggests that epilepsy-specific preintervention evaluations are underused. Randomized controlled trials and population-based studies have demonstrated worse short-term functional outcomes after routine intervention on unruptured AVMs or CCMs when compared with conservative management. The role of invasive therapy for IVM-related epilepsy has yielded mixed results. Case series have reported high estimates of seizure freedom although these results have not been replicated in controlled observational studies. Randomized controlled trials of immediate invasive therapy versus conservative management, in addition to usual care with AEDs and of different types of treatment and their timing, are warranted for AVMs and CCM-related epilepsy.
\end{abstract}

Intracranial vascular malformations (IVMs) encompass a spectrum of blood vessel abnormalities that are of clinical importance because they may cause epileptic seizures and/or hemorrhage. In this narrative review, we will focus on brain arteriovenous malformations (AVMs) and cerebral cavernous malformations (CCMs) because they are the IVMs mainly responsible for epileptic seizures.

Arteriovenous malformations are abnormal tangles of dilated arteries and veins of varying caliber lacking an intervening capillary network, which results in direct arteriovenous shunting from the high-pressure arterial system to the low-

Issue Theme Etiology of Epilepsy; Guest Editors: Philip Smith, MD, FRCP,

FAcadMEd, and Rhys Thomas, BSc, MRCP, $\mathrm{MSc}, \mathrm{PhD}$ pressure venous system. This in turn dilates to form a tangled nidus (Latin nidus, nest). The prevalence of asymptomatic AVMs is approximately 1 in $2000(0.05 \%) .^{1}$ The symptomatic AVM detection rate is 0.89 (95\% confidence interval [CI] 0.701.12) per 100,000 adults per year, split roughly $2: 1$ between hemorrhage versus epileptic seizure(s). ${ }^{2,3}$

Cerebral cavernous malformations are sinusoidal vascular channels devoid of muscular and elastic tissue, lined by a single layer of endothelial cells that lack intervening tight junctions; they are distinguished from capillary telangiectasias by the absence of neural parenchyma within the
Copyright $\odot 2015$ by Thieme Medical Publishers, Inc., 333 Seventh Avenue, New York, NY 10001, USA. Tel: +1(212) 584-4662.
DOI http://dx.doi.org/ $10.1055 / \mathrm{s}-0035-1552621$. ISSN 0271-8235. 
malformation. The prevalence of asymptomatic CCMs is approximately 1 in $625(0.16 \%)^{1}$ The symptomatic CCM detection rate is one-third to one-quarter that of AVMs, 0.24 (95\% CI $0.15-0.38$ ) per 100,000 adults per year, again split roughly 2:1 between hemorrhagic or nonhemorrhagic focal neurologic deficit(s) versus epileptic seizure(s). ${ }^{2}$

Although there is no evidence that AVM detection rates have increased over time, ${ }^{4}$ indirect comparisons between the populations in Scotland 1999 to 2000 and Olmsted County Minnesota 1965 to 1992 confirm that CCM detection has increased over time. ${ }^{2,5}$ This is possibly due to the increasing use of magnetic resonance imaging (MRI), which is especially likely to be the case among patients with epilepsy who are routinely imaged with brain MRI now, but less so in the past. ${ }^{6-8}$

\section{AVMs and CCMs as a Cause of Seizures}

Epileptic seizures are a frequent manifestation of AVMs and CCMs. $^{3}$ However, because a hemorrhage from an AVM or CCM can present with a seizure alone, it is crucial that timely imaging with the correct modality establishes whether hemorrhage has occurred. ${ }^{9}$ Correctly defining the mode of presentation is a critically important step because this carries prognostic and therapeutic implications for the patient: The risk of future hemorrhage is higher if a patient with an AVM or CCM has presented with hemorrhage than if they presented without. ${ }^{10,11}$

Because epileptologists see a disproportionate number of patients with intractable epilepsy in comparison to other neurologists, we often fear the clinical course of epilepsy related to AVMs and CCMs. In this article, we will try to give the broadest perspective possible by summarizing data about patients with AVMs and CCMs concerning the risk of epilepsy after a first unprovoked seizure, the chance of attaining seizure freedom for epilepsy, and comment on the pathogenesis and treatment of epilepsy associated with these common vascular malformations.

\section{Pathogenesis of Seizures and Epilepsy}

\section{The Pathology of Epileptogenesis}

Epileptogenesis is the development and extension of tissue that is capable of generating spontaneous seizures. This includes development of an epilepsy condition and progression after the condition is established. ${ }^{12}$ The epileptogenic zone is the area of brain that is both necessary and sufficient for the generation of epileptic seizures. ${ }^{13,14}$ Removal or disconnection of this region is necessary to achieve seizure freedom. The ictal onset zone refers to the cortical region from which we can objectively demonstrate that seizures originate. ${ }^{13}$ The ictal onset and epileptogenic zones do not necessarily overlap. Patients with a mirror focus may be rendered seizure free through removal of an epileptogenic lesion that constitutes the entire epileptogenic zone. ${ }^{15}$ The irritative zone is the area of the cortex that generates interictal spikes.

Mapping the IVM's position within this network is critical because understanding seizure pathogenesis may influence how epilepsy surgery is planned. For instance, the IVM may exist as an epileptogenic lesion, whereby a simple lesionec- tomy would be expected to yield complete seizure freedom. Alternatively, it may function as a constituent, such as an ictal onset zone, within a larger epileptogenic zone wherein an extended resection would be required for seizure freedom.

\section{Specific Pathogenic Mechanisms}

In general, epileptic seizures originate from zones of cell loss rather than from the more normal appearing adjacent cortex. ${ }^{16}$ This suggests that lesions causing incomplete damage, patchy cell loss, and sclerosis, rather than complete parenchymal destruction, may result in secondary synaptic reorganization, hypersynchrony, and hyperexcitability. ${ }^{17,18}$ Intracranial vascular malformations, potentially as mass lesions and certainly through hemosiderin deposition, can cause chronic irritation and remodeling of the underlying cerebral cortex. ${ }^{17}$ Thus, as long as there is sufficient residual parenchyma, the damaged but still functional cortex may reintegrate and reorganize itself into an epileptogenic network.

Arteriovenous malformations may cause sufficient cell damage to promote epileptogenic pathways through direct shunting of blood from the arterial to the venous compartment. This may lead to chronic ischemia and frank infarction. ${ }^{19,20}$ Impaired perinidal cerebrovascular reserve, not severe enough to result in vascular steal, but significant enough to cause venous congestion and impaired microvascular autoregulation, may additionally result in parenchymal irritation and seizures. ${ }^{21}$ Subclinical hemorrhage or persistent hemosiderin deposition may contribute to chronic cortical irritation and gliosis. ${ }^{22}$

Additional epileptogenic mechanisms play a prominent role in CCM-related epilepsy. Cerebral cavernous malformations seem to have a greater propensity to cause chronic epilepsy compared with other mass lesions. ${ }^{23}$ There is no evidence to suggest that CCMs have intrinsic epileptogenicity or that they exert an epileptogenic effect simply as space-occupying masses; instead, chronic hemosiderin deposition through leaky endothelial junctions ${ }^{24,25}$ may promote a chronic epilepsy state due to iron deposition and generation of free radicals. ${ }^{26}$ In this model of epilepsy, elevated concentrations of serine and glycine in the peripheral zones of $\mathrm{CCMs}^{27}$ and perilesional albumin leakage ${ }^{28}$ were suggested to promote hyperexcitability.

Occasionally, there is dual epileptogenic pathology in association with IVM-related epilepsy. The coexistence of IVMs and focal cortical dysplasia was deemed frequent enough to warrant its own category (FCD type IIIc) in the 2011 International League Against Epilepsy (ILAE) classification scheme. ${ }^{29}$ Intracranial vascular malformations may also occur with other epileptogenic lesions, such as mesial temporal lobe sclerosis ${ }^{30}$ and glioneuronal tumors. ${ }^{31}$

There are reports of rare instances in which patients with AVM-related epilepsy later developed semiologically different seizures from a distant seizure focus, ${ }^{32}$ while coincident mesiotemporal bursts and continuous spiking have been recorded using intraoperative electrocorticography in patients with CCM-related epilepsy. ${ }^{33}$ These reports provide some theoretical support for the potential benefit of early intensive treatment of IVM-related epilepsy; however, in general, attempts to establish truly "antiepileptogenic" strategies have so far proven unsuccessful. ${ }^{34}$ 


\section{Epidemiology and Risk Factors for Seizures and Epilepsy}

\section{Arteriovenous Malformations}

\section{Presentation Due to a Seizure}

The median percentage of patients with AVMs presenting with a seizure in hospital-based studies is $30 \%$ (interquartile range [IQR] 22-35\% ${ }^{35-62}$; an inflated estimate compared with that reported in population-based studies, which by nature, are less prone to selection bias (median 14\%; IQR 1224\%; - Fig. 1A). ${ }^{3,5,63-65}$ Factors that have been associated with a seizure presentation include male sex, ${ }^{41,66}$ younger age, ${ }^{41,67}$ temporal ${ }^{3,41,60}$ or frontal lobe ${ }^{60}$ AVM nidus location, an AVM nidus diameter $>3 \mathrm{~cm},{ }^{41,66}$ superficial or cortical location, ${ }^{60,66,68}$ middle cerebral artery feeders, ${ }^{68}$ an absence

$$
\text { Study }
$$

\section{Clinic}

Andrade-Souza 2006

Crawford 1986

Eisenschenk 1998

Englot 2012

Galletti 2013

Garcin 2012

Ghossoub 2001

Heikkinen 1989

Heros 1990

Holmeister 2000

Hofmeister 2000

Hofmeister 2000

Hofmeister 2000

Hoh 2002

Hyun 2012

Kida 2000

Kjellberg 1983

Korosue 1994

Kurita 1998

Le Feuvre 2007

Lim 2006

Lv 2010

Miserocchi 1984

Pertuiset 1979

Piepgras 1993

Schaeuble 2004

Steiner 1992

Sutcliffe 1992

Thorpe 2000

Yang 2012

Zeiler 2011

Subtotal $\left(1^{\wedge} 2=94.7 \%, p=0.000\right)$

Population

Brown Jr 1996

Hillman 2001

Jessurun 1993

Josephson 2011

Ondra 1990

Subtotal $\left(I^{n} 2=61.6 \%, p=0.034\right)$

Heterogeneity between groups: $p=0.003$

Overall $\left(1^{\wedge} 2=94.0 \%, p=0.000\right)$;
Proportion (95\% Cl)

$0.61(0.45,0.74)$

$0.18(0.14,0.22)$

$0.33(0.25,0.43)$

$0.22(0.19,0.26)$

$0.31(0.23,0.40)$

$0.29(0.22,0.37)$

$0.30(0.27,0.33)$

$0.22(0.16,0.30)$

$0.36(0.29,0.44)$

$0.33(0.26,0.40)$

$0.33(0.28,0.38)$

$0.37(0.32,0.42)$

$0.44(0.35,0.53)$

$0.33(0.29,0.38)$

$0.22(0.18,0.26)$

$0.13(0.10,0.16)$

$0.26(0.21,0.33)$

$0.34(0.28,0.41)$

$0.13(0.10,0.18)$

$0.35(0.23,0.49)$

$0.18(0.14,0.24)$

$0.28(0.20,0.37)$

$0.26(0.20,0.33)$

$0.38(0.31,0.45)$

$0.25(0.20,0.30)$

$0.25(0.20,0.30)$

$0.04(0.02,0.07)$

$0.30(0.23,0.38)$

$0.35(0.27,0.44)$

$0.53(0.46,0.61)$

$0.35(0.25,0.47)$

Median 0.30

(IQR 0.22-0.35)

$0.12(0.06,0.25)$

$0.15(0.10,0.22)$

$0.12(0.03,0.34)$

$0.24(0.19,0.30)$

$0.24(0.18,0.31)$

Median 0.14

(IQR 0.12-0.24)

$0.28(0.24,0.31)$

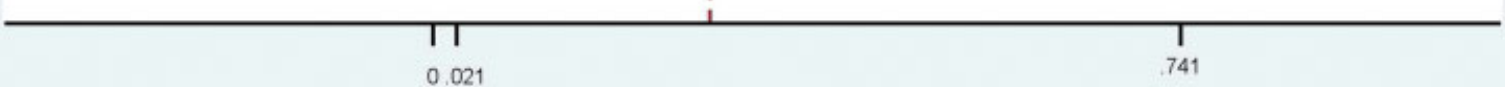

\section{A}

Fig. 1 (A, B) Forest plot of the percentage of patients presenting with a seizure as the first manifestation of their arteriovenous malformation (A) or cerebral cavernous malformation (B), stratified by patient source (clinic or population-based). A formal meta-analysis was not possible due to significant statistical heterogeneity. Median proportions (including interquartile ranges; IQRs) presenting with a seizure are reported in lieu of a pooled estimate. $\mathrm{Cl}$, confidence interval. 


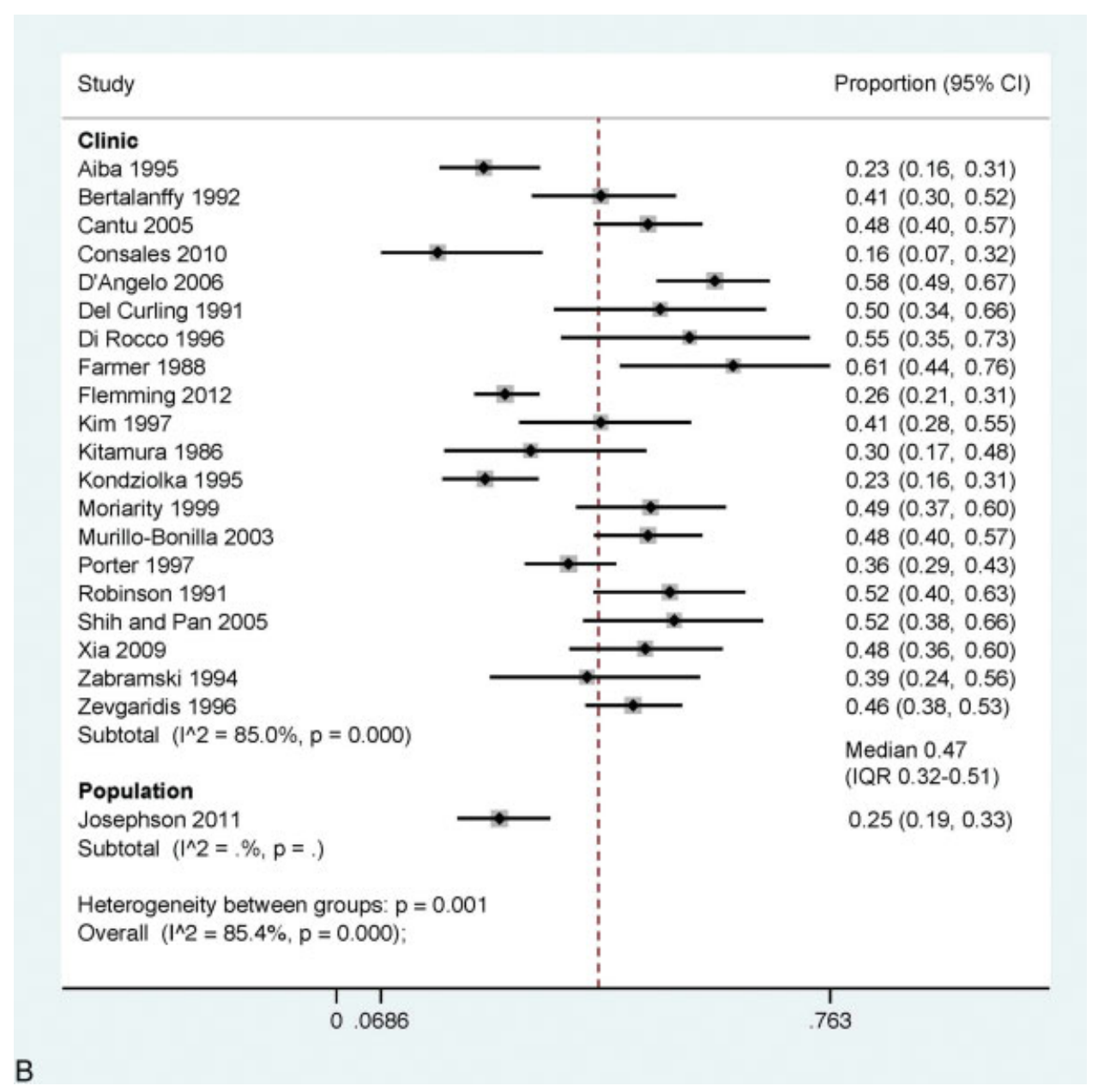

Fig. 1 (Continued)

of associated aneurysms, ${ }^{66,68}$ the presence of a venous varix/ varices, ${ }^{66,68}$ and superficial venous drainage ${ }^{66}$ (-Table $\mathbf{1}$ ).

\section{First-Ever Seizure}

The 5-year prospective risk of a first-ever seizure is estimated to be $8 \%$ (95\% CI $0-20 \%$ ) following presentation with an unruptured, incidentally discovered AVM. ${ }^{3}$ Patients with a prior intracerebral hemorrhage (ICH) or a focal neurologic deficit are at significantly higher risk $^{3,69}$ with an estimated 5year risk of $23 \%$ (95\% CI 9-37\%). ${ }^{3}$ The 5 -year risk is particularly high for patients with acute symptomatic seizures secondary to ICH at the time of presentation (48\%; 95\% CI 19-77\%) and with temporal lobe AVMs (odds ratio [OR] 6.5; 95\% CI 1.8$23)^{3}$

\section{Epilepsy}

Not all patients presenting with a first-ever seizure will subsequently develop epilepsy. The estimated 10 - and 20 year risks of de novo epilepsy were $11 \%$ and $18 \%$, respectively, according to a study of 343 patients diagnosed from 1941 to $1948 .^{59}$ No patient presenting with a nonhemorrhagic focal neurologic deficit or an incidentally discovered AVM developed de novo epilepsy over this time frame.

More recent prospective, population-based data have estimated the 5-year risk of developing epilepsy following a first seizure attributed to an unruptured AVM to be 58\% (95\% CI $40-76 \%)^{3}$ The risk of epilepsy may be higher for females, 59 those with a younger age at AVM diagnosis, ${ }^{69}$ and those with a history of AVM surgery (57\% vs. $11 \%$ 10-year risk, $p<0.001)^{69}$

\section{Cerebral Cavernous Malformations}

Presentation Due to a Seizure

The median percentage of patients with CCMs presenting with a seizure in hospital-based studies is 47\% (IQR 32-51\%) 70-89; an estimate that is again inflated compared with that reported in a population-based study (25\%; 95\% CI 1933\%; - Fig. 1B). ${ }^{3}$ Factors associated with a seizure presentation in individual studies include male sex, ${ }^{85}$ multiple CCMs, ${ }^{3}$ supratentorial CCMs, ${ }^{82}$ superficial CCMs, ${ }^{82}$ and involvement of cerebral cortex ${ }^{90}$ (-Table 2 ). 


\section{First-Ever Seizure}

The annual risk of a first-ever CCM-related epileptic seizure has been imprecisely defined because of the paucity of patients with an incidentally detected CCM in cohort studies and the low event rate. One hospital-based study found this risk to be $2.4 \%$ per patient-year $(95 \% \mathrm{CI}$ unknown $) .{ }^{82}$ The only population-based study found the 5-year risk from time of first diagnosis of an incidental, ruptured CCM was $4 \%$ (95\% CI $0-10 \%$, and this was not significantly higher following presentation with an intracerebral hemorrhage or focal neurologic deficit (6\%, 95\% CI 0-14\%). ${ }^{3}$

\section{Epilepsy}

The 5-year risk of developing epilepsy in patients with no history of ICH or a focal neurologic deficit has been estimated at $94 \%$ ( $95 \%$ Cl $84-100 \%)$. This risk is significantly higher than that reported for AVMs $(p=0.02)$, and most of the events occur within the year following the initial seizure. ${ }^{3}$

\section{Investigations}

\section{Neuroimaging}

The diagnosis of an IVM typically requires timely neuroimaging. A hemorrhage may initially be detected on computed tomography (CT). Suspicion of an AVM may be raised through identification of hyperdense serpentine vascular structures or nidal or vascular calcifications. ${ }^{91}$

Magnetic resonance imaging permits anatomical localization of the AVM nidus, and may reveal parenchymal signatures of hemorrhage that can help identify whether an old symptomatic focal neurologic deficit was attributable to AVM-related intracerebral hemorrhage. ${ }^{91,92}$ Magnetic resonance imaging is the diagnostic modality of choice for detecting CCMs, which are traditionally considered to be "angiographically occult." ${ }^{33}$ Repeated symptomatic and asymptomatic hemorrhage is a defining characteristic of CCMs. The ferromagnetic properties of the evolving process of hemosiderin deposition and calcification of the surrounding parenchyma results in heterogeneities of the local magnetic field that can be exploited by MRI ${ }^{94}$ to classify CCMs into four categories based on their appearance on T1- and T2weighted conventional spin echo and gradient echo sequences. ${ }^{88}$

Angiographic imaging (CT and MR angiography [MRA] and intra-arterial catheter digital subtraction angiography [IADSA]) can identify AVMs by demonstrating a nidus and early arteriovenous shunting. ${ }^{92}$ Although IADSA is traditionally considered the reference standard imaging modality for AVMs, CT and MRA appear comparable for identifying AVMs following intracerebral hemorrhage. ${ }^{95}$ Some form of angiography is prudent when an IVM is suspected on basic imaging to distinguish AVM from CCM.

Positron emission tomography (PET) and single-photon emission computed tomography (SPECT) can be useful imaging tools for presurgical evaluations ${ }^{96-98}$ because they help to map ictal onset, and potentially, the epileptogenic zone. ${ }^{99-101}$ These forms of functional imaging have been used to limit complications from AVM resections, ${ }^{102}$ and their inclusion in

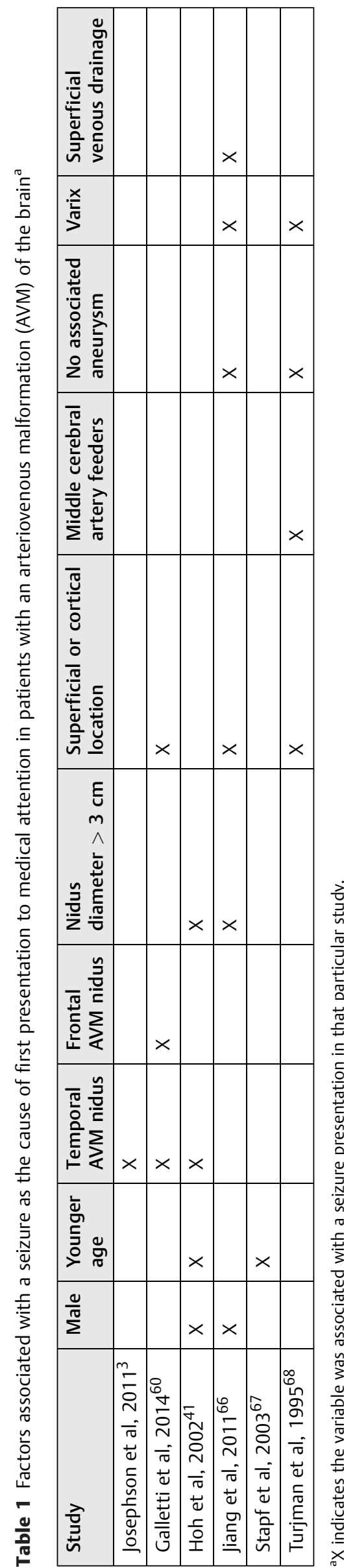


Table 2 Factors associated with a seizure at first presentation to medical attention in patients with a cerebral cavernous malformation (CCM)

\begin{tabular}{|l|l|l|l|l|l|}
\hline Study & Male & Multiple CCMs & Supratentorial CCMs & Superficial CCMs & Involvement of cerebral cortex \\
\hline Josephson et al, $2011^{3}$ & & $\mathrm{X}$ & & & \\
\hline Moriarity et al, $1999^{82}$ & & & $\mathrm{X}$ & $\mathrm{X}$ & \\
\hline Robinson et al, $1991^{85}$ & $\mathrm{X}$ & & & & \\
\hline Menzler et al, $2010^{90}$ & & & & & $\mathrm{X}$ \\
\hline
\end{tabular}

routine presurgical protocols for CCM-related epilepsy has been advocated. ${ }^{103}$ However, further research is warranted to help discern the expected changes in cerebral perfusion and metabolism attributable to the IVM from other abnormalities that may reliably define the ictal onset or epileptogenic zones.

\section{Video-Electroencephalography (Video-EEG) Monitoring}

Video-electroencephalography (EEG) monitoring may be useful if the diagnosis of epilepsy is uncertain, if an IVM is one of two or more potential structural causes of seizures, or if epilepsy surgery is planned. ${ }^{104}$ The patient's usual seizures should be recorded and concurrent video and EEG data are used for surgical localization. ${ }^{105}$ Unfortunately, there are few data available to assess the impact of routine video-EEG on seizure-free outcomes in IVM-related epilepsy. This information would be valuable because routine presurgical workup incorporating video-EEG and standardized volumetric MRI sequences appears underused in IVM-related epilepsy ${ }^{106}$ and may reveal unanticipated dual pathology, such as hippocampal sclerosis or focal cortical dysplasia, or multiple CCMs.

\section{Treatment}

\section{Medical Management}

\section{Arteriovenous Malformations}

Patients with an unruptured AVM and a first-ever seizure now meet the new International League Against Epilepsy's definition of epilepsy ${ }^{3,107}$ because their 5-year risk of a second seizure is $58 \%$ (95\% CI $40-76 \%)^{3}$ The risk may be even higher for women and younger patients, so routine prescription of AEDs could be considered for this population. A population-based study found that the chance of achieving 2-year seizure freedom over 5 years of follow-up following a diagnosis of epilepsy (based on the occurrence of two or more seizures and no history of ICH or a focal neurologic deficit) was $45 \%$ (95\% CI 20-70\%); $91 \%$ of the patients studied were prescribed an AED. ${ }^{3}$ An older study found that patients with AVM-related epilepsy appeared to have a comparable, if not better, response to medical management than patients with other focal brain lesions, with up to $78 \%$ achieving 1 -year seizure freedom. ${ }^{108}$

\section{Cerebral Cavernous Malformations}

Almost all patients with a CCM who suffer a first-ever seizure and have no history of ICH develop epilepsy. Hence, immediate AEDs after a first-ever CCM-related seizure appears justi- fied and has been recommended by the ILAE task force. ${ }^{109} \mathrm{~A}$ population-based study found that the chance of achieving 2year seizure freedom over 5 years of follow-up in conservatively managed patients with CCM-related epilepsy and no history of ICH ( $97 \%$ of whom were prescribed AEDs) was $47 \%$ (95\% CI 27-67\%), ${ }^{3}$ whereas studies from single institutions have found that up to $60 \%$ of patients can be well controlled on AEDs. ${ }^{110,111}$

\section{Interventional Management}

Vascular surgery, embolization, and radiosurgical procedures are conventionally used to reduce the future risk of hemorrhage conferred by vascular malformations. It has been assumed that by proxy these procedures may also have a positive impact on the patient's epilepsy. However, the risk of seizures and epilepsy stems from fundamentally different processes than the risk of $\mathrm{ICH}$. Pathological changes to the surrounding parenchyma and the extent of the epileptogenic zone exert a profound influence on the postoperative chances of achieving seizure freedom. It is imperative to resect or disconnect the epileptogenic zone completely to eradicate seizures. Hence, more extensive resections, rather than simple removal of the IVM, are frequently required to achieve acceptable rates of seizure freedom.

\section{Arteriovenous Malformations}

The annual risk of ICH from an unruptured AVM appears to be $1.3 \%$ (95\% CI 1.0-1.7\%), while that for ruptured AVMs is $4.8 \%$ (95\% CI 3.9-5.9\%) according to an individual patient data meta-analysis from four centers $(n=2525$; 6,074 patientyears follow-up). ${ }^{11}$ In the ARUBA (A Randomized Trial of Unruptured Brain AVMs) randomized controlled trial and Scottish observational population-based study, medical management has been shown to be superior to AVM interventional therapy (neurosurgery, embolization, or stereotactic radiosurgery) for prevention of ICH and death in the short term, ${ }^{112,113}$ so enthusiasm for interventional management for unruptured AVMs may decline. These results need to be borne in mind when contemplating surgery to obliterate unruptured AVMs that have presented with epilepsy, although the long-term effects of interventional treatment on seizure outcomes remain to be described in the ARUBA randomized-controlled trial and Scottish population-based study. ${ }^{112,113}$

Two studies have directly compared conservative medical management with AEDs to interventional management for AVM-related epilepsy. ${ }^{114,115}$ Both were observational studies, one from the United States (which compared surgery to 
Table 3 Rates per 100 person years $(95 \% \mathrm{Cl})$ or median proportion $(95 \% \mathrm{Cl})$ of complications following interventional therapy for AVMs $^{118}$ for $\mathrm{CCMs}^{121}$

\begin{tabular}{|c|c|c|c|c|}
\hline & & Surgery & Stereotactic radiosurgery & Embolization \\
\hline \multicolumn{5}{|l|}{ AVM } \\
\hline & Case fatality & $1.1(0.87-1.3)$ & $0.5(0.43-0.58)$ & $0.96(0.67-1.4)$ \\
\hline & $\mathrm{ICH}$ & $0.18(0.10-0.30)$ & $1.7(1.5-1.8)$ & $1.7(1.3-2.3)$ \\
\hline & Persistent focal neurologic deficit ${ }^{\mathrm{a}}$ & $7.4 \%(0.0-40 \%)$ & $5.1 \%(0.0-21 \%)$ & $6.6 \%(0.0-18 \%)$ \\
\hline \multicolumn{5}{|l|}{ CCM } \\
\hline & Case fatality ${ }^{\mathrm{b}}$ & $0.3(0.02-0.4)$ & $0.3(0.2-0.6)$ & Not applicable \\
\hline & $\mathrm{ICH}^{\mathrm{c}}$ & $1.1(0.8-1.4)$ & $3.2(2.7-3.9)$ & Not applicable \\
\hline & Persistent focal neurological deficit & $4.3(3.7-4.9)$ & $1.2(0.8-1.7)$ & Not applicable \\
\hline
\end{tabular}

Abbreviations: AVMs, arteriovenous malformations; CCMs, cerebral cavernous malformations; $\mathrm{CI}$, confidence interval; ICH, intracerebral hemorrhage. ${ }^{\text {a }}$ Reported as median proportion $(95 \% \mathrm{Cl})$.

${ }^{\mathrm{b}}$ Case fatality directly attributable to CCM or treatment.

'Symptomatic ICH only.

medical management) and one from the United Kingdom (which compared any type of interventional treatment for AVMs to medical management). These two studies had similar sample sizes, population demographics, and AVM characteristics. Similar rates of AVM obliteration were obtained in the intervention cohort in each study $\left(75 \%^{115}\right.$ vs. $\left.72 \%\right) .{ }^{114}$ During follow-up periods that ranged from 4.6 years to 13 years, neither study found a significant difference in the chance of achieving seizure freedom (risk ratio [RR] 1.11, 95\% CI 0.69-1.80 ${ }^{114}$; and RR 0.84, 95\% CI 0.47-1.49). ${ }^{115}$

Many hospital-based case series have reported outcomes of AVM treatment for epilepsy management, but very few have been population-based or included control groups of patients whose AVMs were not treated. A recent systematic review and meta-analysis has attempted to quantify rates of seizure-freedom according to each interventional modality. A total of $73 \%$ (mean follow-up of $4.5 \pm 1.9$ years) were seizurefree (duration unclear) following microsurgery, 62.9\% (mean follow-up $3.6 \pm 1.5$ years) following stereotactic radiosurgery, and $50 \%$ (mean follow-up $3.8 \pm 2.3$ years) following embolization, ${ }^{116}$ but these data were extremely susceptible to selection and reporting biases, so these outcomes may well be overestimates. Complete AVM obliteration appeared to be associated with better chances of seizure freedom following stereotactic radiosurgery, but there were insufficient data available to study this in patients undergoing microsurgery or embolization. ${ }^{116}$ Few studies have addressed the role of multimodality interventional approaches to AVM-related epilepsy. Retrospective, single center experiences suggest that up to $70 \%$ can become seizure free using multimodality AVM therapy, ${ }^{41,117}$ although these estimates are again highly susceptible to selection and reporting biases.

The estimated benefits of intervention must be weighed against the putative risks. In those with no preintervention history of seizures, the proportion of patients with new onset postintervention seizures was $9.9 \%$ (54/547 patients) following microsurgery, 5.1\% (29/568 patients) following stereotactic radiosurgery, and $33 \%$ (4/12 patients) following embolization according to one systematic review. ${ }^{116}$ Further- more, a systematic review of 142 cohorts (comprising 13,698 patients with a 46,314 patient-years follow-up) indicated appreciable risks of case fatality, ICH, and permanent neurologic deficits following all three forms of invasive therapy (-Table 3). ${ }^{118}$

Therefore, available knowledge leaves us uncertain about the benefits of AVM surgery for seizure prevention and control overall, and a subgroup who benefit the most remains to be identified.

\section{Cerebral Cavernous Malformations}

The 5-year risk of a first-ever and recurrent intracerebral hemorrhage from a CCM is estimated at $2.4 \%$ (95\% CI 0.0-5.7\%) and $29.5 \%$ (4.1-55\%), respectively. ${ }^{10}$ Functional deficits are mild following CCM-related ICH and do not appear to accumulate with recurrent hemorrhage. ${ }^{10}$ Interventional therapy (surgery or stereotactic radiosurgery) does not appear to have a dramatic effect ( $\mathrm{RR} \geq 10$ or a $p$ value $<0.01$ ) on the risk of ICH recurrence in nonrandomized studies, ${ }^{119}$ and surgical excision of CCMs has been associated with worse functional outcomes that are sustained over at least 2 years during 5 years of follow-up. ${ }^{120}$ Furthermore, a recent systematic review and meta-analysis of 63 cohorts reporting on 3,424 patients found not inconsiderable risks of death, hemorrhage, and permanent neurologic deficits following surgical excision or stereotactic radiosurgery for CCM ( - Table 3). ${ }^{121}$ There are insufficient comparative studies, ${ }^{119}$ and no randomized trials, on which to establish the optimal treatment approach. Hence, the same therapeutic uncertainties about AVM management also apply to CCMs.

A systematic review found that the literature on CCM treatment for intractable epilepsy is plagued by inconsistent definitions, poor descriptions of preoperative evaluation, limited details of the surgical technique, and a lack of standardized outcome measures. ${ }^{106}$ Given the nonrandomized, uncontrolled design of most of these studies, the best interventional approach remains uncertain, with some groups advocating a pure lesionectomy for selected cases, ${ }^{122-125}$ whereas others favor a standard extended lesionectomy 
with concurrent resection of the hemosiderin-stained parenchyma. ${ }^{111,126}$ Some suggest the surgical technique should be guided by seizure frequency (with more aggressive resections warranted in cases of drug-resistant epilepsy), ${ }^{127}$ whereas others have promoted a two-step approach whereby a pure lesionectomy is first conducted with invasive-EEG monitoring followed by more extensive resections for those who fail the first stage. ${ }^{125}$ Intraoperative electrocorticography may be required for cases involving "eloquent" cortex or the temporal lobe. ${ }^{125}$ In particular, lesionectomy with associated intraoperative electrocorticography may improve outcomes for temporal lobe CCMs, as up to 72.7 to $100 \%$ of patients may achieve an Engel 1 outcome (free of disabling seizures). ${ }^{128}$ Furthermore, there is increasing evidence suggesting that the time from the first seizure to the resection of epileptogenic CCMs and the number of seizures occurring before a resection is performed may negatively correlate with the likelihood of a seizure-free outcome. ${ }^{109,129}$ This suggests that early resection could be associated with better outcomes.

Multiple CCMs do not necessarily rule out an operative approach. A detailed presurgical work up that includes videoEEG monitoring is warranted, especially for patients with multiple CCMs, to identify the epileptogenic region. In some cases, a single CCM responsible for the epilepsy can be identified and safely resected with excellent seizure outcome. ${ }^{130}$ The presence of dual pathology may require additional modifications to the surgical approach. A combined lesionectomy and standard anterior temporal lobectomy may be required for patients with a CCM and mesial temporal sclerosis, ${ }^{127}$ whereas a tailored resection of both the area of cortical dysplasia and the CCM appears necessary in patients with FCD type IIIc. ${ }^{131}$ In these scenarios, an operation for mesial temporal lobe epilepsy related to a CCM may be even more effective that than the same procedure performed for mesial temporal lobe sclerosis. ${ }^{132}$

Stereotactic radiosurgery has been used to treat CCMs, ${ }^{133}$ although its effect on the underlying pathology and prevention of CCM recurrence remains unknown. The overall effect of radiosurgery appears more modest than surgery in indirect comparisons, ${ }^{134-136}$ and was not statistically different in one direct comparison. ${ }^{137}$

\section{Conclusions and Future Directions}

We know that IVMs are important causes of seizures and epilepsy, and their identification following a first seizure has implications for AED treatment. But many uncertainties remain. Larger studies of the many potential predictors of seizure risk are needed, as are studies of associations with better treatment outcomes, but the greatest need is for randomized controlled trials.

Single-center studies of uncommon conditions, such as AVMs and CCMs, often lack the power to detect small but clinically meaningful results, leading to a proliferation of type II errors (false-negative results). ${ }^{138}$ Meta-analyses can be used to identify small but meaningful effects that may have otherwise gone undetected, but these have been challenging because of inconsistent definitions of clinical presentation and reporting of outcomes. ${ }^{106}$ Future prospective, multicenter studies should therefore aim to include unselected population-based cohorts; enroll patients at consistent time points within the disease natural history; use clearly defined terminology for clinical presentation, ${ }^{9}$ including consensus definitions of epilepsy ${ }^{107}$ and drug-resistant epilepsy ${ }^{139}$; robustly characterize the untreated natural history of these conditions using consistent, objective measures of seizure freedom ${ }^{140,141}$; and be of sufficient power to provide reliable estimates of prognostic variables. Recommended duration should be $\geq 1$ year and completeness of follow-up should be $\geq 90 \%$. In the absence of these studies, individual patient data meta-analysis may permit use of existing data. It is the optimal meta-analytic technique because it involves central processing of individual patient data from both published and unpublished datasets, uses consistent analytical approaches across cohorts, avoids the limitations of metaregression, and permits investigations of subgroups of interest. ${ }^{142-145}$

Finally, we need randomized controlled trials of AVM and CCM treatment for the prevention of seizures. Higher-quality observational studies have failed to identify a dramatic treatment effect between conservative and medical management, and between different interventional techniques for CCMs in particular. ${ }^{114,116,119}$ Randomized trials could resolve the issue of whether conservative medical management is superior to interventional therapy in cases where there is doubt, and whether early surgery is preferable to delayed surgery. For those with drug-resistant epilepsy, a randomized-controlled trial conducted using epilepsy surgical rather than vascular surgical techniques ${ }^{146}$ would help to resolve the controversy regarding the optimal resection margins for $\mathrm{CCMs}^{121,147}$ and may help guide standard multimodality AVM treatment.

In the absence of high-quality data from RCTs, a standard epilepsy presurgical evaluation involving scalp video-EEG monitoring, and where necessary, invasive EEG recordings, PET, SPECT, and magnetoencephalography, is likely to be equally effective for IVM-related drug-resistant epilepsy as it is for people with other forms of epilepsy. ${ }^{129,148}$

\section{References}

1 Morris Z, Whiteley WN, Longstreth WT Jr, et al. Incidental findings on brain magnetic resonance imaging: systematic review and meta-analysis. BMJ 2009;339:b3016

2 Al-Shahi R, Bhattacharya JJ, Currie DG, et al; Scottish Intracranial Vascular Malformation Study Collaborators. Prospective, population-based detection of intracranial vascular malformations in adults: the Scottish Intracranial Vascular Malformation Study (SIVMS). Stroke 2003;34(5):1163-1169

3 Josephson CB, Leach JP, Duncan R, Roberts RC, Counsell CE, AlShahi Salman R; Scottish Audit of Intracranial Vascular Malformations (SAIVMs) steering committee and collaborators. Seizure risk from cavernous or arteriovenous malformations: prospective population-based study. Neurology 2011;76(18):1548-1554

4 Gabriel RA, Kim H, Sidney S, et al. Ten-year detection rate of brain arteriovenous malformations in a large, multiethnic, defined population. Stroke 2010;41(1):21-26

5 Brown RD Jr, Wiebers DO, Torner JC, O'Fallon WM. Incidence and prevalence of intracranial vascular malformations in Olmsted County, Minnesota, 1965 to 1992. Neurology 1996;46(4): 949-952 
6 National Institute for Health and Care Excellence.. The epilepsies: the diagnosis and management of the epilepsies in adults and children in primary and secondary care. NICE clinical guideline 137. London, UK: National Institute for Health and Care Excellence; 2013

7 Scottish Intercollegiate Guidelines Network.. Diagnosis and management of epilepsy in adults: a national clinical guideline. SIGN guideline 70. Edinburgh, UK: Scottish Intercollegiate Guidelines Network; 2003

8 Krumholz A, Wiebe S, Gronseth G, et al; Quality Standards Subcommittee of the American Academy of Neurology; American Epilepsy Society. Practice Parameter: evaluating an apparent unprovoked first seizure in adults (an evidence-based review): report of the Quality Standards Subcommittee of the American Academy of Neurology and the American Epilepsy Society. Neurology 2007;69(21):1996-2007

9 Al-Shahi Salman R, Berg MJ, Morrison L, Awad IA; Angioma Alliance Scientific Advisory Board. Hemorrhage from cavernous malformations of the brain: definition and reporting standards. Stroke 2008;39(12):3222-3230

10 Al-Shahi Salman R, Hall JM, Horne MA, et al; Scottish Audit of Intracranial Vascular Malformations (SAIVMs) collaborators. Untreated clinical course of cerebral cavernous malformations: a prospective, population-based cohort study. Lancet Neurol 2012; 11(3):217-224

11 Kim H, Al-Shahi Salman R, McCulloch CE, Stapf C, Young WL; MARS Coinvestigators. Untreated brain arteriovenous malformation: patient-level meta-analysis of hemorrhage predictors. Neurology 2014;83(7):590-597

12 Pitkänen A. Therapeutic approaches to epileptogenesis-hope on the horizon. Epilepsia 2010;51(Suppl 3):2-17

13 Carreno M, Lüders H. General principles of presurgical evaluation. In: Lüders H, Comair YG, eds. Epilepsy Surgery. 2nd ed. Philadelphia, PA: Lippincott Williams \& Wilkins; 2001

14 Rosenow F, Lüders H. Presurgical evaluation of epilepsy. Brain 2001;124(Pt 9):1683-1700

15 Gilmore R, Morris H III, Van Ness PC, Gilmore-Pollak W, Estes M. Mirror focus: function of seizure frequency and influence on outcome after surgery. Epilepsia 1994;35(2):258-263

16 Babb TL, Brown WJ, Pretorius J, Davenport C, Lieb JP, Crandall PH. Temporal lobe volumetric cell densities in temporal lobe epilepsy. Epilepsia 1984;25(6):729-740

17 Engel J Jr. Seizures and Epilepsy. 2nd ed. New York, NY: Oxford University Press; 2013

18 Salazar AM, Jabbari B, Vance SC, Grafman J, Amin D, Dillon JD. Epilepsy after penetrating head injury. I. Clinical correlates: a report of the Vietnam Head Injury Study. Neurology 1985; 35(10):1406-1414

19 Herzig R, Bogousslavsky J, Maeder P, et al. Intracranial arterial and arteriovenous malformations presenting with infarction. Lausanne Stroke Registry Study. Eur J Neurol 2005;12(2): 93-102

20 Zschocke S. [Pathogenesis of epileptic seizures in patients with cerebral arteriovenous angioma. The role of cerebral ischemia (author's transl)]. Fortschr Neurol Psychiatr Grenzgeb 1974; 42(9):433-453

21 Fierstra J, Conklin J, Krings T, et al. Impaired peri-nidal cerebrovascular reserve in seizure patients with brain arteriovenous malformations. Brain 2011;134(Pt 1):100-109

22 Yeh HS, Kashiwagi S, Tew JM Jr, Berger TS. Surgical management of epilepsy associated with cerebral arteriovenous malformations. J Neurosurg 1990;72(2):216-223

23 Leone MA, Ivashynka AV, Tonini MC, et al; ARES (Alcohol Related Seizures) study group. Risk factors for a first epileptic seizure symptomatic of brain tumour or brain vascular malformation. A case control study. Swiss Med Wkly 2011;141:w13155

24 Awad I, Jabbour P. Cerebral cavernous malformations and epilepsy. Neurosurg Focus 2006;21(1):e7
25 Clatterbuck RE, Eberhart CG, Crain BJ, Rigamonti D. Ultrastructural and immunocytochemical evidence that an incompetent bloodbrain barrier is related to the pathophysiology of cavernous malformations. J Neurol Neurosurg Psychiatry 2001;71(2):188-192

26 Willmore LJ, Sypert GW, Munson JB. Recurrent seizures induced by cortical iron injection: a model of posttraumatic epilepsy. Ann Neurol 1978;4(4):329-336

27 von Essen C, Rydenhag B, Nyström B, Mozzi R, van Gelder N, Hamberger A. High levels of glycine and serine as a cause of the seizure symptoms of cavernous angiomas? J Neurochem 1996; 67(1):260-264

28 Seiffert E, Dreier JP, Ivens S, et al. Lasting blood-brain barrier disruption induces epileptic focus in the rat somatosensory cortex. J Neurosci 2004;24(36):7829-7836

29 Blümcke I, Thom M, Aronica E, et al. The clinicopathologic spectrum of focal cortical dysplasias: a consensus classification proposed by an ad hoc Task Force of the ILAE Diagnostic Methods Commission. Epilepsia 2011;52(1):158-174

30 Li LM, Cendes F, Andermann F, et al. Surgical outcome in patients with epilepsy and dual pathology. Brain 1999;122(Pt 5):799-805

31 Giulioni M, Marucci G, Martinoni M, et al. Seizure outcome in surgically treated drug-resistant mesial temporal lobe epilepsy based on the recent histopathological classifications. J Neurosurg 2013;119(1):37-47

32 Yeh HS, Privitera MD. Secondary epileptogenesis in cerebral arteriovenous malformations. Arch Neurol 1991;48(11): 1122-1124

33 Ferrier $\mathrm{CH}$, Aronica E, Leijten FS, et al. Electrocorticography discharge patterns in patients with a cavernous hemangioma and pharmacoresistent epilepsy. J Neurosurg 2007;107(3):495-503

34 Loescher W. Strategies for antiepileptogenesis: Antiepileptic drugs versus novel approaches evaluated in post-status epilepticus models of temporal lobe epilepsy. In Noebels JL, Avoli M, Rogawski MA, et al , eds. Jasper's Basic Mechanisms of the Epilepsies. 4th ed. Bethesda, MD: National Center for Biotechnology Information; 2012

35 Andrade-Souza YM, Ramani M, Scora D, Tsao MN, TerBrugge K, Schwartz ML. Radiosurgical treatment for rolandic arteriovenous malformations. J Neurosurg 2006;105(5):689-697

36 Eisenschenk S, Gilmore RL, Friedman WA, Henchey RA. The effect of LINAC stereotactic radiosurgery on epilepsy associated with arteriovenous malformations. Stereotact Funct Neurosurg 1998; 71(2):51-61

37 Englot DJ, Young WL, Han SJ, McCulloch CE, Chang EF, Lawton MT. Seizure predictors and control after microsurgical resection of supratentorial arteriovenous malformations in 440 patients. Neurosurgery 2012;71(3):572-580, discussion 580

38 Ghossoub M, Nataf F, Merienne L, et al. [Evolution of epileptic seizures associated with cerebral arteriovenous malformations after radiosurgery]. Neurochirurgie 2001;47(2-3 Pt 2):344-349

39 Heikkinen ER, Konnov B, Melnikov L, et al. Relief of epilepsy by radiosurgery of cerebral arteriovenous malformations. Stereotact Funct Neurosurg 1989;53(3):157-166

40 Heros RC, Korosue K, Diebold PM. Surgical excision of cerebral arteriovenous malformations: late results. Neurosurgery 1990; 26(4):570-577, discussion 577-578

41 Hoh BL, Chapman PH, Loeffler JS, Carter BS, Ogilvy CS. Results of multimodality treatment for 141 patients with brain arteriovenous malformations and seizures: factors associated with seizure incidence and seizure outcomes. Neurosurgery 2002;51(2): 303-309, discussion 309-311

42 Hyun SJ, Kong DS, Lee JI, Kim JS, Hong SC. Cerebral arteriovenous malformations and seizures: differential impact on the time to seizure-free state according to the treatment modalities. Acta Neurochir (Wien) 2012;154(6):1003-1010

43 Kida Y, Kobayashi T, Tanaka T, Mori Y, Hasegawa T, Kondoh T. Seizure control after radiosurgery on cerebral arteriovenous malformations. J Clin Neurosci 2000;7(Suppl 1):6-9 
44 Kjellberg RN, Hanamura T, Davis KR, Lyons SL, Adams RD. Braggpeak proton-beam therapy for arteriovenous malformations of the brain. N Engl J Med 1983;309(5):269-274

45 Korosue K, Hara Y, Tamaki N, Heros RC. Long-term prognosis of seizures after complete surgical resection of AVMs of the brain. Japanese Journal of Neurosurgery 1994;3:10-17

46 Kurita H, Kawamoto S, Suzuki I, et al. Control of epilepsy associated with cerebral arteriovenous malformations after radiosurgery. J Neurol Neurosurg Psychiatry 1998;65(5):648-655

47 Le Feuvre D, Taylor A. Target embolization of AVMs: Identification of sites and results of treatment. Interv Neuroradiol 2007;13(4): 389-394

48 Lim YJ, Lee CY, Koh JS, Kim TS, Kim GK, Rhee BA. Seizure control of Gamma Knife radiosurgery for non-hemorrhagic arteriovenous malformations. Acta Neurochir Suppl (Wien) 2006;99:97-101

49 Lv X, Li Y, Jiiang C, Yang X, Wu Z. Brain arteriovenous malformations and endovascular treatment: effect on seizures. Interv Neuroradiol 2010;16(1):39-45

50 Pertuiset B, Sichez JP, Philippon J, Fohanno D, Horn Y. [Mortality and morbidity after complete surgical removal of 162 intracranial arteriovenous malformations (author's transl)]. Rev Neurol (Paris) $1979 ; 135(4): 319-327$

51 Piepgras DG, Sundt TM Jr, Ragoowansi AT, Stevens L. Seizure outcome in patients with surgically treated cerebral arteriovenous malformations. J Neurosurg 1993;78(1):5-11

52 Schäuble B, Cascino GD, Pollock BE, et al. Seizure outcomes after stereotactic radiosurgery for cerebral arteriovenous malformations. Neurology 2004;63(4):683-687

53 Steiner L, Lindquist C, Adler JR, Torner JC, Alves W, Steiner M. Clinical outcome of radiosurgery for cerebral arteriovenous malformations. J Neurosurg 1992;77(1):1-8

54 Sutcliffe JC, Forster DM, Walton L, Dias PS, Kemeny AA. Untoward clinical effects after stereotactic radiosurgery for intracranial arteriovenous malformations. Br J Neurosurg 1992;6(3):177-185

55 Thorpe ML, Cordato DJ, Morgan MK, Herkes GK. Postoperative seizure outcome in a series of 114 patients with supratentorial arteriovenous malformations. J Clin Neurosci 2000;7(2):107-111

56 Yang SY, Kim DG, Chung HT, Paek SH. Radiosurgery for unruptured cerebral arteriovenous malformations: long-term seizure outcome. Neurology 2012;78(17):1292-1298

57 Zeiler FA, McDonald PJ, Kaufmann A, et al. Gamma knife for cerebral arteriovenous malformations at a single centre. Can J Neurol Sci 2011;38(6):851-857

58 Miserocchi G, Sironi VA, Ravagnati L. [Epilepsy in arteriovenous malformations: considerations on 174 cases]. Bollettino - Lega Italiana contro l'Epilessia 1984;45-46:267-269 [Italian]

59 Crawford PM, West CR, Chadwick DW, Shaw MDM. Arteriovenous malformations of the brain: natural history in unoperated patients. J Neurol Neurosurg Psychiatry 1986;49(1):1-10

60 Galletti F, Costa C, Cupini LM, et al. Brain arteriovenous malformations and seizures: an Italian study. J Neurol Neurosurg Psychiatry 2014;85(3):284-288

61 Hofmeister C, Stapf C, Hartmann A, et al. Demographic, morphological, and clinical characteristics of 1289 patients with brain arteriovenous malformation. Stroke 2000;31(6):1307-1310

62 Garcin B, Houdart E, Porcher R, et al. Epileptic seizures at initial presentation in patients with brain arteriovenous malformation. Neurology 2012;78(9):626-631

63 Hillman J. Population-based analysis of arteriovenous malformation treatment. J Neurosurg 2001;95(4):633-637

64 Jessurun GA, Kamphuis DJ, van der Zande FH, Nossent JC. Cerebral arteriovenous malformations in The Netherlands Antilles. High prevalence of hereditary hemorrhagic telangiectasia-related single and multiple cerebral arteriovenous malformations. Clin Neurol Neurosurg 1993;95(3):193-198

65 Ondra SL, Troupp H, George ED, Schwab K. The natural history of symptomatic arteriovenous malformations of the brain: a 24year follow-up assessment. J Neurosurg 1990;73(3):387-391
66 Jiang P, Lv X, Wu Z, et al. Characteristics of brain arteriovenous malformations presenting with seizures without acute or remote hemorrhage. Neuroradiol J 2011;24(6):886-888

67 Stapf C, Khaw AV, Sciacca RR, et al. Effect of age on clinical and morphological characteristics in patients with brain arteriovenous malformation. Stroke 2003;34(11):2664-2669

68 Turjman F, Massoud TF, Sayre JW, Viñuela F, Guglielmi G, Duckwiler G. Epilepsy associated with cerebral arteriovenous malformations: a multivariate analysis of angioarchitectural characteristics. AJNR Am J Neuroradiol 1995;16(2):345-350

69 Crawford PM, West CR, Shaw MD, Chadwick DW. Cerebral arteriovenous malformations and epilepsy: factors in the development of epilepsy. Epilepsia 1986;27(3):270-275

70 Aiba T, Tanaka R, Koike T, Kameyama S, Takeda N, Komata T. Natural history of intracranial cavernous malformations. J Neurosurg 1995;83(1):56-59

71 Bertalanffy H, Kühn G, Scheremet R, Seeger W. Indications for surgery and prognosis in patients with cerebral cavernous angiomas. Neurol Med Chir (Tokyo) 1992;32(9):659-666

72 Cantu C, Murillo-Bonilla L, Arauz A, Higuera J, Padilla J, Barinagarrementeria F. Predictive factors for intracerebral hemorrhage in patients with cavernous angiomas. Neurol Res 2005;27(3): 314-318

73 Consales A, Piatelli G, Ravegnani M, et al. Treatment and outcome of children with cerebral cavernomas: a survey on 32 patients. Neurol Sci 2010;31(2):117-123

74 D'Angelo VA, De Bonis C, Amoroso R, et al. Supratentorial cerebral cavernous malformations: clinical, surgical, and genetic involvement. Neurosurg Focus 2006;21(1):e9

75 Del Curling OJr, Kelly DL Jr, Elster AD, Craven TE. An analysis of the natural history of cavernous angiomas. J Neurosurg 1991;75(5): 702-708

76 Di Rocco C, Iannelli A, Tamburrini G. Cavernomas of the central nervous system in children. A report of 22 cases. Acta Neurochir (Wien) 1996;138(11):1267-1274, discussion 1273-1274

77 Farmer JP, Cosgrove GR, Villemure JG, Meagher-Villemure K, Tampieri D, Melanson D. Intracerebral cavernous angiomas. Neurology 1988;38(11):1699-1704

78 Flemming KD, Link MJ, Christianson TJ, Brown RD Jr. Prospective hemorrhage risk of intracerebral cavernous malformations. Neurology 2012;78(9):632-636

79 Kim DS, Park YG, Choi JU, Chung SS, Lee KC. An analysis of the natural history of cavernous malformations. Surg Neurol 1997; 48(1):9-17, discussion 17-18

80 Kitamura K, Fukui M, Oka K, et al. Hemangiomas of the central nervous system in Japan: an epidemiological and clinicopathological study with special reference to venous and cavernous malformations. Neurosurg Rev 1986;9(3):221-231

81 Kondziolka D, Lunsford LD, Kestle JR. The natural history of cerebral cavernous malformations. J Neurosurg 1995;83(5): 820-824

82 Moriarity JL, Wetzel M, Clatterbuck RE, et al. The natural history of cavernous malformations: a prospective study of 68 patients. Neurosurgery 1999;44(6):1166-1171, discussion $1172-1173$

83 Murillo-Bonilla LM, Cantú-Brito C, Arauz-Góngora A, HigueraCalleja J, Padilla-Rubio J, Barinagarrementeria-Aldatz F. [Cavernous angioma. Clinical observations and prognosis of 133 patients]. Rev Invest Clin 2003;55(4):387-393

84 Porter PJ, Willinsky RA, Harper W, Wallace MC. Cerebral cavernous malformations: natural history and prognosis after clinical deterioration with or without hemorrhage. J Neurosurg 1997; 87(2):190-197

85 Robinson JR, Awad IA, Little JR. Natural history of the cavernous angioma. J Neurosurg 1991;75(5):709-714

86 Shih YH, Pan DH. Management of supratentorial cavernous malformations: craniotomy versus gammaknife radiosurgery. Clin Neurol Neurosurg 2005;107(2):108-112 
87 Xia C, Zhang R, Mao Y, Zhou L. Pediatric cavernous malformation in the central nervous system: report of 66 cases. Pediatr Neurosurg 2009;45(2):105-113

88 Zabramski JM, Wascher TM, Spetzler RF, et al. The natural history of familial cavernous malformations: results of an ongoing study. J Neurosurg 1994;80(3):422-432

89 Zevgaridis D, van Velthoven V, Ebeling U, Reulen HJ. Seizure control following surgery in supratentorial cavernous malformations: a retrospective study in 77 patients. Acta Neurochir (Wien) 1996;138(6):672-677

90 Menzler K, Chen X, Thiel P, et al. Epileptogenicity of cavernomas depends on (archi-) cortical localization. Neurosurgery 2010; 67(4):918-924

91 Mossa-Basha M, Chen J, Gandhi D. Imaging of cerebral arteriovenous malformations and dural arteriovenous fistulas. Neurosurg Clin N Am 2012;23(1):27-42

92 Ferrara AR. Brain arteriovenous malformations. Radiol Technol 2011;82(6): 543MR-556MR

93 Rigamonti D, Hadley MN, Drayer BP, et al. Cerebral cavernous malformations. Incidence and familial occurrence. N Engl J Med 1988;319(6):343-347

94 Sigal R, Krief O, Houtteville JP, Halimi P, Doyon D, Pariente D. Occult cerebrovascular malformations: follow-up with MR imaging. Radiology 1990;176(3):815-819

95 Josephson CB, White PM, Krishan A, Al-Shahi Salman R. Computed tomography angiography or magnetic resonance angiography for detection of intracranial vascular malformations in patients with intracerebral haemorrhage. Cochrane Database Syst Rev 2014;9:CD009372

96 Desai A, Bekelis K, Thadani VM, et al. Interictal PET and ictal subtraction SPECT: sensitivity in the detection of seizure foci in patients with medically intractable epilepsy. Epilepsia 2013; 54(2):341-350

97 Duncan JS. Imaging and epilepsy. Brain 1997;120(Pt 2):339-377

98 Wehner T, Lüders $\mathrm{H}$. Role of neuroimaging in the presurgical evaluation of epilepsy. J Clin Neurol 2008;4(1):1-16

99 Kalamangalam GP, Pestana Knight EM, Visweswaran S, Gupta A. Noninvasive predictors of subdural grid seizure localization in children with nonlesional focal epilepsy. J Clin Neurophysiol 2013;30(1):45-50

100 la Fougère $C$, Rominger $A$, Förster $S$, Geisler J, Bartenstein P. PET and SPECT in epilepsy: a critical review. Epilepsy Behav 2009; 15(1):50-55

101 Pittau F, Grouiller F, Spinelli L, Seeck M, Michel CM, Vulliemoz S. The role of functional neuroimaging in pre-surgical epilepsy evaluation. Front Neurol 2014;5:31

102 Leblanc R, Meyer E. Functional PET scanning in the assessment of cerebral arteriovenous malformations. Case report. J Neurosurg 1990;73(4):615-619

103 Alonso-Vanegas MA, Cisneros-Franco JM, Otsuki T. Surgical management of cavernous malformations presenting with drugresistant epilepsy. Front Neurol 2011;2:86

104 Ryvlin P, Cross JH, Rheims S. Epilepsy surgery in children and adults. Lancet Neurol 2014;13(11):1114-1126

105 Cascino GD. Video-EEG monitoring in adults. Epilepsia 2002;43 (Suppl (Suppl 3):80-93

106 von der Brelie C, Schramm J. Cerebral cavernous malformations and intractable epilepsy: the limited usefulness of current literature. Acta Neurochir (Wien) 2011;153(2):249-259

107 Fisher RS, Acevedo C, Arzimanoglou A, et al. ILAE official report: a practical clinical definition of epilepsy. Epilepsia 2014;55(4): 475-482

108 Stephen LJ, Kwan P, Brodie MJ. Does the cause of localisationrelated epilepsy influence the response to antiepileptic drug treatment? Epilepsia 2001;42(3):357-362

109 Rosenow F, Alonso-Vanegas MA, Baumgartner C, et al; Surgical Task Force, Commission on Therapeutic Strategies of the ILAE. Cavernoma-related epilepsy: review and recommendations for management-report of the Surgical Task Force of the ILAE Commission on Therapeutic Strategies. Epilepsia 2013;54(12): 2025-2035

110 Churchyard A, Khangure M, Grainger K. Cerebral cavernous angioma: a potentially benign condition? Successful treatment in 16 cases. J Neurol Neurosurg Psychiatry 1992;55(11): 1040-1045

111 Stavrou I, Baumgartner C, Frischer JM, Trattnig S, Knosp E. Longterm seizure control after resection of supratentorial cavernomas: a retrospective single-center study in 53 patients. Neurosurgery 2008;63(5):888-896, discussion 897

112 Mohr JP, Parides MK, Stapf C, et al; international ARUBA investigators. Medical management with or without interventional therapy for unruptured brain arteriovenous malformations (ARUBA): a multicentre, non-blinded, randomised trial. Lancet 2014; 383(9917):614-621

113 Al-Shahi Salman R, White PM, Counsell CE, et al; Scottish Audit of Intracranial Vascular Malformations Collaborators. Outcome after conservative management or intervention for unruptured brain arteriovenous malformations. JAMA 2014;311(16): 1661-1669

114 Josephson CB, Bhattacharya JJ, Counsell CE, et al; Scottish Audit of Intracranial Vascular Malformations (SAIVMs) steering committee and collaborators. Seizure risk with AVM treatment or conservative management: prospective, population-based study. Neurology 2012;79(6):500-507

115 Murphy MJ. Long-term follow-up of seizures associated with cerebral arteriovenous malformations. Results of therapy. Arch Neurol 1985;42(5):477-479

116 Baranoski JF, Grant RA, Hirsch LJ, et al. Seizure control for intracranial arteriovenous malformations is directly related to treatment modality: a meta-analysis. J Neurointerv Surg 2014; 6(9):684-690

117 Hyun SJ, Kong DS, Lee JI, Kim JS, Hong SC. Cerebral arteriovenous malformations and seizures: differential impact on the time to seizure-free state according to the treatment modalities. Acta Neurochir (Wien) 2012;154(6):1003-1010

118 van Beijnum J, van der Worp HB, Buis DR, et al. Treatment of brain arteriovenous malformations: a systematic review and metaanalysis. JAMA 2011;306(18):2011-2019

119 Poorthuis M, Samarasekera N, Kontoh K, et al. Comparative studies of the diagnosis and treatment of cerebral cavernous malformations in adults: systematic review. Acta Neurochir (Wien) 2013;155(4):643-649

120 Moultrie F, Horne MA, Josephson CB, et al; Scottish Audit of Intracranial Vascular Malformations (SAIVMs) steering committee and collaborators. Outcome after surgical or conservative management of cerebral cavernous malformations. Neurology 2014;83(7):582-589

121 Poorthuis MH, Klijn CJ, Algra A, Rinkel GJ, Al-Shahi Salman R. Treatment of cerebral cavernous malformations: a systematic review and meta-regression analysis. J Neurol Neurosurg Psychiatry 2014;85(12):1319-1323

122 Casazza M, Broggi G, Franzini A, et al. Supratentorial cavernous angiomas and epileptic seizures: preoperative course and postoperative outcome. Neurosurgery 1996;39(1):26-32, discussion 32-34

123 Chang EF, Gabriel RA, Potts MB, Garcia PA, Barbaro NM, Lawton MT. Seizure characteristics and control after microsurgical resection of supratentorial cerebral cavernous malformations. Neurosurgery 2009;65(1):31-37, discussion 37-38

124 Cohen DS, Zubay GP, Goodman RR. Seizure outcome after lesionectomy for cavernous malformations. J Neurosurg 1995;83(2): 237-242

125 Ferroli P, Casazza M, Marras C, Mendola C, Franzini A, Broggi G. Cerebral cavernomas and seizures: a retrospective study on 163 patients who underwent pure lesionectomy. Neurol Sci 2006; 26(6):390-394 
126 Baumann CR, Schuknecht B, Lo Russo G, et al. Seizure outcome after resection of cavernous malformations is better when surrounding hemosiderin-stained brain also is removed. Epilepsia 2006;47(3):563-566

127 Yeon JY, Kim JS, Choi SJ, Seo DW, Hong SB, Hong SC. Supratentorial cavernous angiomas presenting with seizures: surgical outcomes in 60 consecutive patients. Seizure 2009;18(1):14-20

128 San-Juan D, Díaz-Nuñez IC, Ojeda-Baldéz M, et al. Utility of electrocorticography in the surgical treatment of cavernomas presenting with pharmacoresistant epilepsy. Epileptic Disord 2014;16(3):245-260

129 Stefan H, Hammen T. Cavernous haemangiomas, epilepsy and treatment strategies. Acta Neurol Scand 2004;110(6):393-397

130 Rocamora R, Mader I, Zentner J, Schulze-Bonhage A. Epilepsy surgery in patients with multiple cerebral cavernous malformations. Seizure 2009;18(4):241-245

131 Chen DJ, Severson E, Prayson RA. Cavernous angiomas in chronic epilepsy associated with focal cortical dysplasia. Clin Neuropathol 2013;32(1):31-36

132 Menzler K, Thiel P, Hermsen A, et al. The role of underlying structural cause for epilepsy classification: clinical features and prognosis in mesial temporal lobe epilepsy caused by hippocampal sclerosis versus cavernoma. Epilepsia 2011;52(4):707-711

133 Nagy G, Kemeny AA. Stereotactic radiosurgery of intracranial cavernous malformations. Neurosurg Clin N Am 2013;24(4): 575-589

134 Liu KD, Chung WY, Wu HM, et al. Gamma knife surgery for cavernous hemangiomas: an analysis of 125 patients. J Neurosurg 2005;102(Suppl):81-86

135 Régis J, Bartolomei F, Kida Y, et al. Radiosurgery for epilepsy associated with cavernous malformation: retrospective study in 49 patients. Neurosurgery 2000;47(5):1091-1097

136 Wang P, Zhang F, Zhang H, Zhao H. Gamma knife radiosurgery for intracranial cavernous malformations. Clin Neurol Neurosurg 2010;112(6):474-477

137 Hsu PW, Chang CN, Tseng CK, et al. Treatment of epileptogenic cavernomas: surgery versus radiosurgery. Cerebrovasc Dis 2007; 24(1):116-120, discussion 121
138 Egger M, Smith GD. Meta-Analysis. Potentials and promise. BMJ 1997;315(7119):1371-1374

139 Kwan P, Arzimanoglou A, Berg AT, et al. Definition of drug resistant epilepsy: consensus proposal by the ad hoc Task Force of the ILAE Commission on Therapeutic Strategies. Epilepsia 2010;51(6):1069-1077

140 Engel JC, Ness PCV, Rasmussen TB, Ojemann LM. Outcome with respect to epileptic seizures. In: Engel J Jr, ed. Surgical treatment of the epilepsies. New York, NY: Raven Press; 1993

141 Wieser HG, Blume WT, Fish D, et al; Commission on Neurosurgery of the International League Against Epilepsy (ILAE). ILAE Commission Report. Proposal for a new classification of outcome with respect to epileptic seizures following epilepsy surgery. Epilepsia 2001;42(2):282-286

142 Stewart LA, Clarke MJ; Cochrane Working Group. Practical methodology of meta-analyses (overviews) using updated individual patient data. Stat Med 1995;14(19):2057-2079

143 Stewart LA, Parmar MK. Meta-analysis of the literature or of individual patient data: is there a difference? Lancet 1993; 341(8842):418-422

144 Stewart LA, Tierney JF. To IPD or not to IPD? Advantages and disadvantages of systematic reviews using individual patient data. Eval Health Prof 2002;25(1):76-97

145 Simmonds MC, Higgins JP, Stewart LA, Tierney JF, Clarke MJ, Thompson SG. Meta-analysis of individual patient data from randomized trials: a review of methods used in practice. Clin Trials 2005;2(3):209-217

146 Schwartz TH. Epilepsy surgeons, rather than vascular neurosurgeons, should operate on cavernous malformations that cause seizures-a modest proposal. Epilepsy Curr 2010;10(3):59-60

147 Englot DJ, Han SJ, Lawton MT, Chang EF. Predictors of seizure freedom in the surgical treatment of supratentorial cavernous malformations. J Neurosurg 2011;115(6):1169-1174

148 von der Brelie C, Malter MP, Niehusmann P, Elger CE, von Lehe M, Schramm J. Surgical management and long-term seizure outcome after epilepsy surgery for different types of epilepsy associated with cerebral cavernous malformations. Epilepsia 2013;54(9):1699-1706 